NASA Technical Memorandum 104585

\title{
Contamination Control and Plume Assessment of Low-Energy Thrusters
}

John J. Scialdone

NASA Goddard Space Flight Center

Greenbelt, Maryland

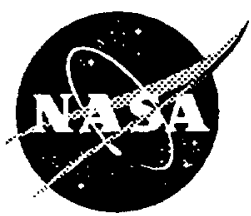

National Aeronautics and Space Administration

Goddard Space Flight Center

Greenbelt, Maryland 20771 


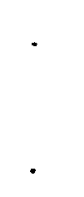




\title{
CONTAMINATION CONTROL AND PLUME ASSESSMENT OF LOW-ENERGY THRUSTERS
}

\author{
John J. Scialdone \\ NASA/Goddard Space Flight Center \\ Greenbelt, Maryland 20771
}

\begin{abstract}
Potential contamination of a spacecraft cryogenic surface by a xenon (Xe) ion generator (ref. 1) has been evaluated. The analysis involves the description of the plume exhausted from the generator with its relative component fluxes on the spacecraft surfaces, and verification of the conditions for condensation, adsorption, and sputtering at those locations.

The data describing the plume fluxes and their effects on surfaces were obtained from two sources: the tests (ref. 1) carried out with the Xe generator in a small vacuum chamber to indicate deposits and sputter on monitor slides; and the extensive tests with a mercury $(\mathrm{Hg})$ ion thruster (ref. 2) in a large vacuum chamber. The $\mathrm{Hg}$ thruster tests provided data on the neutrals, on low-energy ion fluxes, on high-energy ion fluxes, and on sputtered materials at several locations within the plume.
\end{abstract}

From these indications, and a technique used in ref. 3 , the value of the angle from the plume centerline, corresponding to half the maximum value at the centerline of the flux under consideration, has been used to describe the plume for each component. The plumes are described by the mass flows, by the distances from the exit plane, and by a power of the cosine of the angle. The derivation of this relation (as indicated in ref. 3 ) was obtained by measuring and fitting the flux produced by a nitrogen plume to $a \cos ^{n} \theta$ function. The nitrogen at different pressures ( 2 to 50 torr) exhausted from various pipe fittings ( 4.7 to $38 \mathrm{~mm}$ in diameter) in a large vacuum chamber, which was maintained at pressures always lower than $10^{-4}$ torr.

Based on these data, the plume of the Xe neutrals has been represented by a cosine squared function of the angle and found to be a possible contamination source for certain surfaces of the spacecraft. The paper indicates the steps used to perform the contamination analysis using the expected fluxes and several kinetic gas relationships. The densities, pressures, velocities, condensation, evaporation, adsorption, and other parameters can be evaluated at specific locations.

The ion generator, according to the manufacturer, has the following characteristics: it releases $0.5 \mathrm{~cm}^{3} / \mathrm{min}$ of Xe at $300 \mathrm{~K}$; it produces a thrust of a few millinewton $(\mathrm{mN})$; it releases low-energy and high-energy plasma with energies of $15 \mathrm{eV}$ and $28 \mathrm{eV}$ respectively, under steady-state conditions; and it has an electromagnetic dipole contained mostly within the generator.
The contamination assessment indicates that for the expected flux, at a critical spacecraft surface located $1 \mathrm{~m}$ away at an angle of $80^{\circ}$ from the plume axis, condensation of $\mathrm{Xe}$ is not possible. However, a fraction of a monolayer can deposit on the surface. The reflected and scattered Xe from the cold surface also cannot deposit on nearby surfaces. Other conclusions derived from the analysis are that the plasma and the generator-sputtered materials are contained within a $40^{\circ}$ field of view.

\section{INTRODUCTION}

Among the many factors to be evaluated for the employment of a plasma ion thruster engine on a spacecraft, one must consider: the potential contamination of nearby surfaces; the charging of the spacecraft by charged particles; the sputtering of surfaces; the modification of the environment by the neutrals and charged particles from the engine; the propulsive force not being applied through the spacecraft center of mass; and the electric fields produced by the engine modifying the environment and inducing objectionable interference frequencies.

In this paper, an evaluation of the contamination hazards of the Xe plasma emitted from an ion generator engine system is carried out, and methods to carry out similar analyses are explained. The specific example of an Xe ion generator, (Figures 1 and 2) suggested for application as a charge discharge system for a spacecraft carrying contamination-sensitive instruments (refs. $1,4,5$ ), has been studied to evaluate some of the effects indicated above.

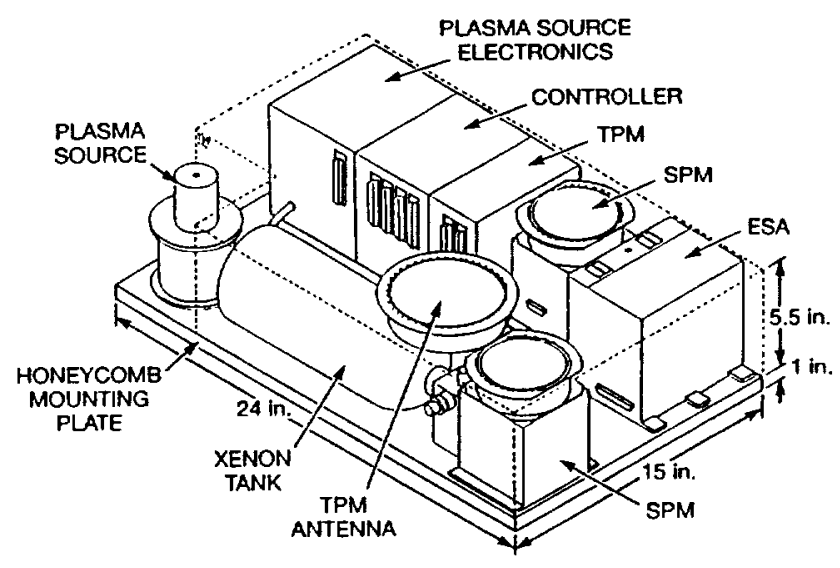

FIGURE 1. CHARGE CONTROL SYSTEM (FROM ROBSON ET AL. (REF. 1), IBID.) 


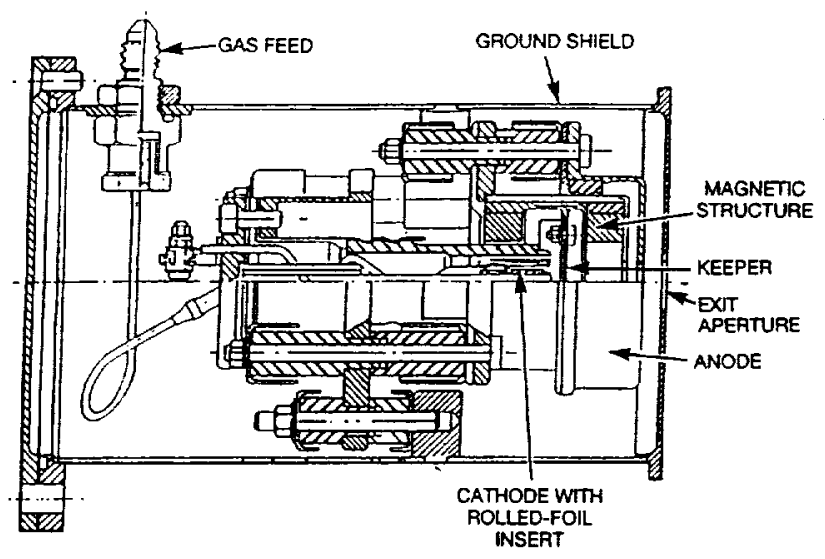

FIGURE 2. CROSS SECTION OF THE FLIGHT PLASMA GENERATOR (FROM ROBSON ET AL. (REF. 1), IBID.)

\section{THRUSTER PARAMETERS}

An ion thruster that provides thrust for attitude control, orbit transfer, and other propulsive functions is characterized by the mass rate, $\dot{\mathrm{m}}$, of the propellant and the propellant exit velocity, $v$. In general, the thrust, $F=\dot{m} v$, from this type of engine is in the microNewton range. The propellant may be $\mathrm{Xe}$ or other suitable gas which can be ionized and confined by magnets or grids. The efflux from the thruster is composed of neutrals, a cold plasma consisting of a lowenergy mix of positive, negative and neutral atoms and electrons, and a high-energy, hot plasma consisting of the same components. The thruster also releases so-called nonpropulsive, sputtered materials.

In general, the effluents will exit with a distribution that may be described with a power of the cosine function. The cold plasma is affected by electromagnetic fields created in the thruster. The particles of the plasma interact with the spacecraft, are neutralized on the surfaces, and then are released after a brief delay. The energies may be of about $15 \mathrm{eV}$ for the cold plasma, and about $28 \mathrm{eV}$ for the hot plasma. The hot plasma may alter, erode, deposit upon, or sputter upon surfaces. The energetic particles are confined within a narrow plume. The nonpropulsive materials are also emitted within a very small angle about the centerline of the exit plume. The nonpropulsive effluents may have energies of $35-40 \mathrm{eV}$ and may consist of molybdenum (Mo), rhenium ( $\mathrm{Re})$, barium-cobalt $\left(\mathrm{BaCO}_{3}\right)$, and others, which can sputter on surfaces in their paths. The electromagnetic fields produced by the plasma flow and by the engine's internal magnets may change the trajectory of the contaminants. Also, they may cause interference at some nearby instrument, disrupt communication, and produce certain disturbing low frequencies.

\section{CONTAMINATION EVALUATION HAZARDS}

For a gaseous source with a given volumetric flow rate $\mathrm{q}\left(\mathrm{cm}^{3} / \mathrm{s}\right)$ and gas with mole mass $M$, the corresponding mass flow rate is $\dot{\mathrm{m}}=\mathrm{QM} / \mathrm{V}(\mathrm{g} / \mathrm{s})$ where $\mathrm{V}=22.4 \times 10^{3}\left(\mathrm{~cm}^{3} / \mathrm{mol}\right)$. The adiabatic exit flow velocity of the gas expanding into vacuum is $v=[2 \gamma \mathrm{RT} / \mathrm{M}(1-\gamma)]^{1 / 2}$ where $\mathrm{T}(\mathrm{K})$ is the temperature acquired by the gas at the source, $\gamma=c_{p} / c_{v}$ is the ratio of the gas' specific heat, which is 1.66 for monoatomic gas, and 1.4 for diatomic gas, and $\mathrm{R}=8.31 \times 10^{7}(\mathrm{erg} / \mathrm{mole} / \mathrm{K})$ is the gas constant.

The plume distribution of the emitted gas can be described approximately by a power of the cosine function. The function was derived using experimental data obtained from measurements in the plume of a low-pressure vent from a pipe (ref. 3). The flux as a function of the angle $\theta\left({ }^{\circ}\right)$ from the plume axis, $\mathrm{r}(\mathrm{cm})$ the distance from the vent exit, is:

$$
\Phi=\frac{\dot{\mathrm{m}}(\mathrm{n}+1)}{2 \pi \mathrm{r}^{2}} \cos ^{\mathrm{n}} \theta
$$

$\left(\mathrm{g} / \mathrm{cm}^{2} / \mathrm{s}\right)$

where the exponent $n(n=1,2,3, \ldots)$ represents the divergence of the plume shape from the cosine to the first power distribution.

The value of $n$, as indicated in ref. 3 , can be obtained from a normalized plot of the flux or from any parameter describing the plume as a function of the angle from the plume centerline. The angle $\theta_{1 / 2}$ corresponding to $50 \%$ of the maximum value at the centerline, is a measure of the plume spread. A graphical representation of $\cos ^{n} \theta$ versus angle $\theta$ with $\mathrm{n}$ as a parameter is shown in Figure 3 and can be used to evaluate $n$. Representations of the fluxes in terms of normalized $\Phi / \dot{m}$ and location in an axisymmetrical plane are shown in Figures 5, 6, 7, 8, and 9, for cosine to the $n=$ $1,2,3,4$, and 5 power.

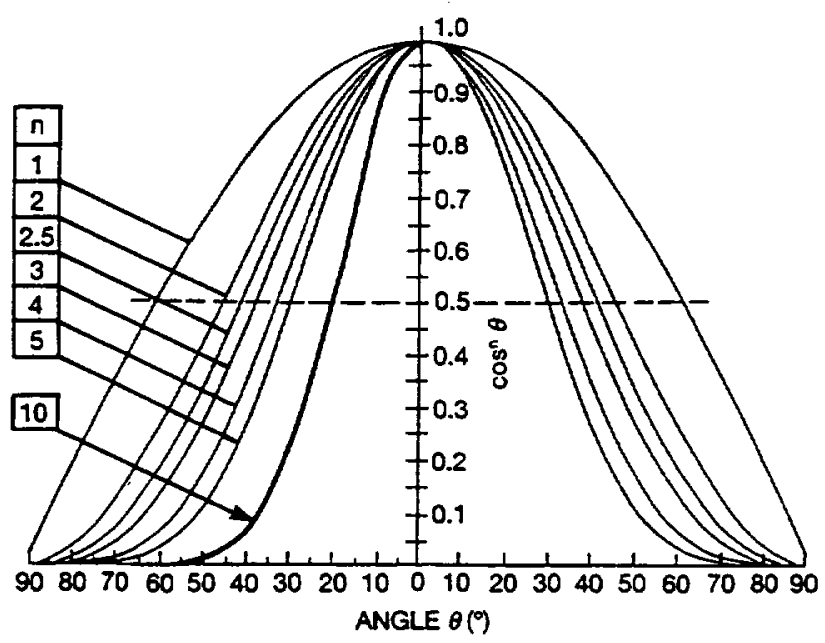

FIGURE 3. $\cos ^{n} \theta$ versus $\theta$. 

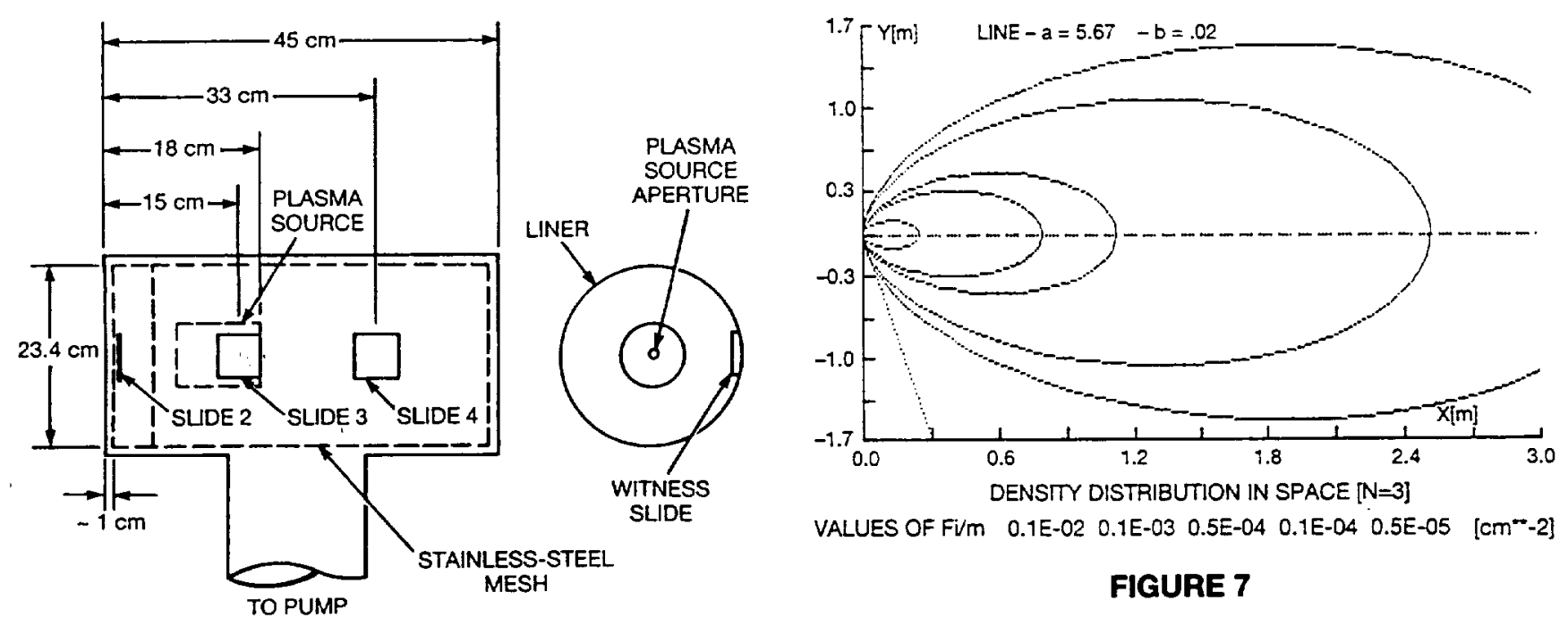

FIGURE 4. POSITIONS OF THE CONTAMINATION "WITNESS" SLIDES DURING THE PLASMA GENERATOR LIFETEST (FROM ROBSON ET AL. (REF. 1), IBID.)

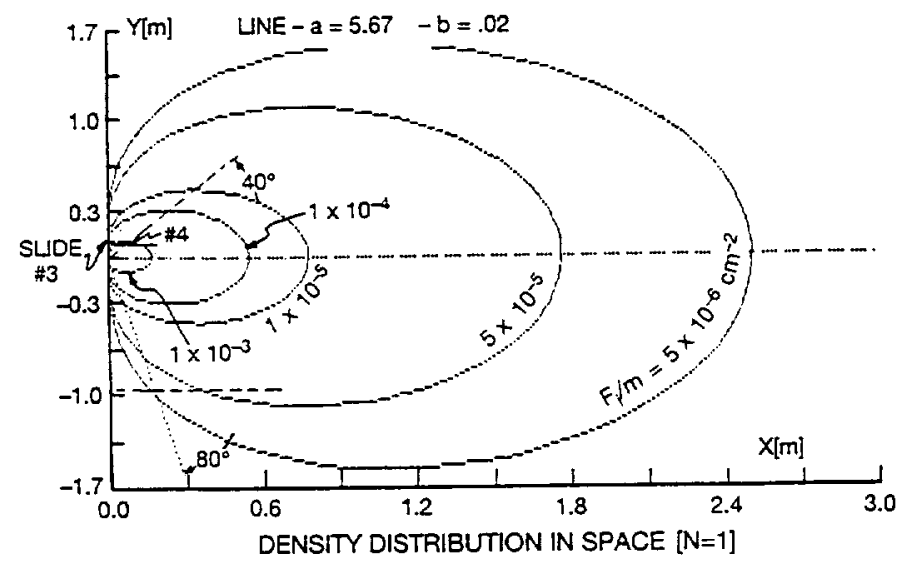

VALUES OF FV/m $\quad 0.1 E-02 \quad 0.1 E-03 \quad 0.5 E-04 \quad 0.1 E-04 \quad 0.5 E-05 \quad\left[\mathrm{~cm}^{m-2}\right.$-2]

FIGURE 5

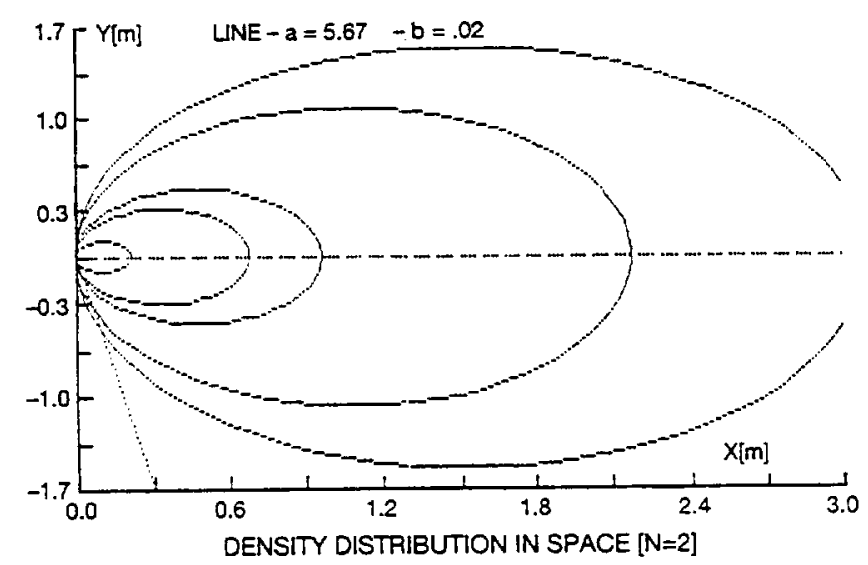

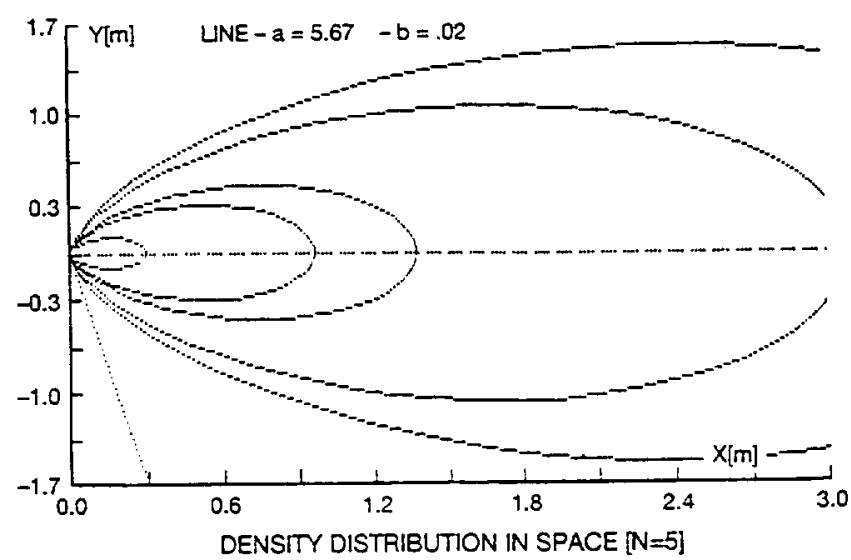

$\begin{array}{lllllll}\text { VALUES OF Fi/m } & 0.1 E-02 & 0.1 E-03 & 0.5 E-04 & 0.1 E-04 & 0.5 E-05 & {\left[\mathrm{~cm}^{--}-2\right]}\end{array}$

\section{FIGURE 9}

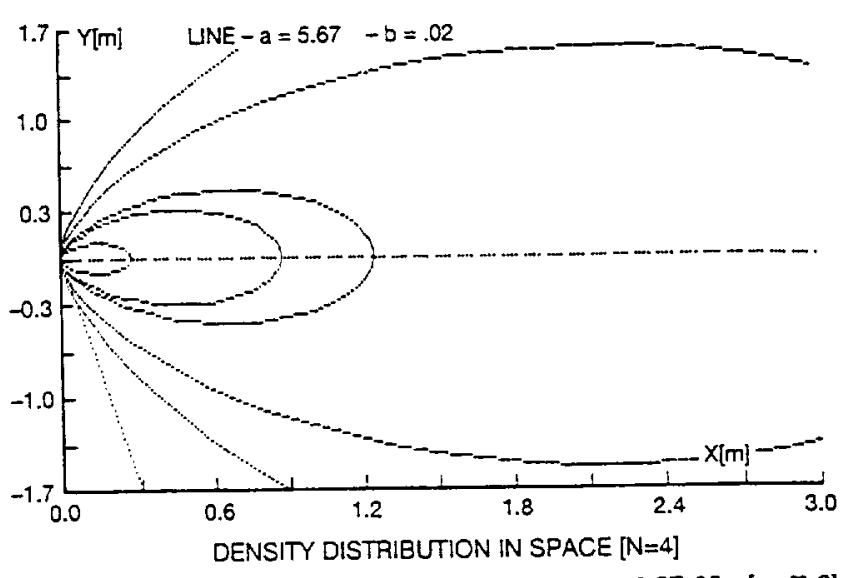

FIGURE 8 
The molecular flux corresponding to the mass flux is:

$$
\dot{i}=\Phi(\mathrm{A} / \mathrm{M})
$$

$\left(\mathrm{cm}^{-2} \mathrm{~s}^{-1}\right)$

where $A=6.03 \times 10^{23}(\mathrm{molec} / \mathrm{mole})$ is the Avogadro number.

The density at a location in the plume can be described by:

$$
\rho=\dot{\mathrm{n}} / \mathrm{v}=\Phi \mathrm{A} / \mathrm{Mv}
$$

with the symbols defined previously. The pressure $P$, using as the reference the atmospheric density for air $\rho_{0}=2.45 \mathrm{x}$ $10^{19}\left(\mathrm{~cm}^{3}\right)$ at $\mathrm{P}_{\mathrm{o}}=760$ torr and $\mathrm{M}_{\mathrm{o}}=28(\mathrm{~g} / \mathrm{mole})$, is:

$$
\mathrm{P}=\mathrm{P}_{\mathrm{o}}\left(\rho \mathrm{M} / \rho_{\mathrm{o}} \mathrm{M}_{\mathrm{o}}\right)
$$

(torr).

A back-flow scatter flux can be esitmated assuming a molecular scatter at the furthermost gas streamline where the flux or the density is known. The portion of the flux directed backward could be estimated very roughly to be 1/6 $\Phi$ accounting for six possible directions of scatter.

On an impinged surface, there is an increased density due to the reflected molecules combining with the arriving molecules. The reflected number and energy depend on the accommodation of the incoming molecules on the surface at its temperature and surface conditions. As a first approximation, one may assume full accommodation at the temperature $\mathrm{T}_{\mathrm{s}}$ of the surface so that $\rho \mathrm{v}=1 / 4 \rho_{\mathrm{e}} \mathrm{v}_{\mathrm{e}}$

where $v=\left[2 \gamma \mathrm{RT}_{\sigma}(\gamma-1) \mathrm{M}\right]^{1 / 2}$,

and $v_{\mathrm{e}}=\left[\frac{\pi}{8} \frac{\mathrm{RT}}{\mathrm{M}}\right]^{1 / 2}$. The density at the surface is then:

$$
\rho_{\mathrm{e}}=4 \rho\left[\frac{2 \pi \gamma}{8(\gamma-1)} \frac{\mathrm{T}_{\mathrm{o}}}{\mathrm{T}_{\mathrm{s}}}\right]^{1 / 2}
$$

and the corresponding pressure:

$$
\mathrm{P}_{\mathrm{e}}=4 \mathrm{P}\left[\frac{2 \pi \gamma}{8(\gamma-1)} \frac{\mathrm{T}_{\mathrm{o}}}{\mathrm{T}_{\mathrm{s}}}\right]^{1 / 2}
$$

\section{Condensation:}

Given the conditions of the impinged gas at surface $\left(\rho_{\mathrm{e}}\right.$, $\mathrm{p}_{\mathrm{e}}, \phi_{\mathrm{e}}, \Theta, \mathrm{n}_{\mathrm{e}}$ ) and the surface temperature $\mathrm{T}_{\mathrm{s}}$, one can obtain the vapor pressure of the gas at the temperature of the surface $P_{s}$, and can calculate the eventual rate of evaporation of the condensed gas, using the Langmuir equation:

$$
\phi_{\mathrm{ev}}=\mathrm{P}_{\mathrm{s}}(\mathrm{M} / \mathrm{T})^{1 / 2} / 17.24 \quad\left(\mathrm{~g} / \mathrm{cm}^{2} / \mathrm{s}\right)
$$

and the flux

$$
\dot{\mathrm{n}}_{\mathrm{e}}=\phi_{\mathrm{ev}}(\mathrm{A} / \mathrm{M})
$$

If $\Phi_{e}>\Phi$ or $P_{s}>P_{e}$; i.e., the evaporation parameters are greater than the impinging parameters, the condensation cannot occur. However, an adsorption of some molecules on the surface can occur. The accumulation described by its thickness is:

$$
\delta=\phi \mathrm{v} \rho
$$

where $\mathrm{t}(\mathrm{s})$ is the accumulation time and $\rho\left(\mathrm{g} / \mathrm{cm}^{3}\right)$ is the density of the condensate.

\section{Adsorption:}

As indicated, if $\mathrm{P}_{\mathrm{s}}>\mathrm{P}_{\mathrm{e}}$, no condensation is possible but adsorption of some molecules can occur. The molecules can be held on the surface by van der Waal forces. At equilibrium, a number of molecules reside on the surface while molecules arrive and leave. The departing molecules sojourn on the surface for a time, $t(s)$, before they leave. The time is a function of an oscillation period, $t_{0} \cong 1 \times 10^{-13}(\mathrm{~s})$, of the atom on the surface; an activation energy, $E$ (cal/mole), the surface temperature, $T$, and the gas constant, $R=1.97$ (cal/K/mole). These are related as follows:

$$
t=t_{0} \exp E / R T
$$

showing that the sojourn time decreases exponentially with the temperature. The atoms residing on the surface are then:

$$
s=\operatorname{atn}
$$

where a is a sticking coefficient and $\dot{n}\left(\mathrm{~cm}^{-2} \mathrm{~s}^{-1}\right)$ is the impinging flux. The number of monolayers can be estimated knowing the diameter of the atom $d(\mathrm{~cm})$, its cross-section area $\mathrm{A}\left(\mathrm{cm}^{2}\right)$ and the number of them fitting a $\mathrm{cm}^{2}$ surface, $\mathrm{N}$. The number of monolayers corresponding to $s$ is then $s / N$.

\section{EXPERIMENTAL DATA}

In the absence of direct data for the Xe charge discharge system, with the exception of test data indicating that no contamination or erosion occurred on slides 3 and 4 (Figure 4) during testing in a $23.4-\mathrm{cm}$-diameter, $46-\mathrm{cm}$-long vacuum chamber, test data obtained at Lewis Research Center (LeRC) with an 8-cm mercury ( $\mathrm{Hg}$ ) thruster (ref. 2), have been used to characterize in general terms the plumes emitted from these ion thrusters. They are those of the nonpropellant particles $(\mathrm{Np})$ of the high-energy ions $(\mathrm{Pb})$ including Group I and the charge exchange ions, Group II; of the low-energy plasma (Px); and of the neutral $\mathrm{P}_{0}$. The $\mathrm{Hg}$ thruster $(\mathrm{M}=200$ $\mathrm{g} / \mathrm{mole}$ ) was an ion auxiliary propulsion system (IAPS) for the USAF-STP-P80-1 mission. The first ionization potential of $\mathrm{Hg}$ is $10.43 \mathrm{eV}$ and the second, $18.75 \mathrm{eV}$. The Xe (M $=131$ ) has the first ionization at $12.2 \mathrm{eV}$ and the second at $21.21 \mathrm{eV}$. The propellant of the Xe thruster consists of $90 \%$ $\mathrm{Xe}$ and 10: hydrogen $(\mathrm{H})$. The Xe generator system does not have an accelerator grid, which according to the designer, accounts for most of the metal efflux and does not employ a high-energy beam.

From those tests showing the pressures, current densities, and fluxes within the $\mathrm{Hg}$ exhaust as measured in large vacuum chambers, the following characterization of the 
plumes has been deduced based on the half-angle values defining the cosine distribution of the plume.

The nonpropulsive sputtered materials $(\mathrm{Np})$ were not present at angles greater than $40^{\circ}, 45 \mathrm{~cm}$ downstream of the thruster exit.

The test on high-energy $\mathrm{Hg}$ ions ( $\mathrm{Pb}$, Group I) indicated that the current density was $50 \%$ of its maximum at an angle of $8^{\circ}$ from the thrust axis and $38 \mathrm{~cm}$ from the exit. This indicates a narrow plume describable with a cosine function to a power of about 70 .

The charge exchange ( $\mathrm{Pb}$, Group II) ions formed by collision of ions among themselves and with neutrals indicated by a $\theta$ of about $37^{\circ}$. The plume cosine power can be represented with an $\mathrm{n}$ of about 4 . A plume with $n=4$ is shown in Figure 8.

The low-energy plasma ions ( $\mathrm{Px}$ ) produced by the charge exchange reaction between the high-energy ions with neutrals appear to show a $\theta_{1 / 2}=30-35^{\circ}$, which requires an $n$ between 5 and 10. A plume for $n=5$ is shown in Figure 9.

The neutrals $\mathrm{Hg}(\mathrm{Po})$, which may be $20-25 \%$ of the total effluent during steady-state operation, appear to have a $\theta_{1 / 2}$ at $45-46^{\circ}$, indicating an $n$ of about 2 . Plume distribution for $n=1$ and 2 are shown in Figures 5 and 6 .

In Figure 5, the locations of the slides used to monitor contamination during the Xe plasma discharge control system tests in the small vacuum chamber are shown. The location of the critical surface at $80 \mathrm{~K}, 100 \mathrm{~cm}$ away from the exit has been shown on the plots. This cold surface would be present with the suggested application of the Xe system.

From this analysis, one concludes that contamination or damage to surfaces will not occur within a relatively large field of view of the discharge system. Contamination on surfaces at a large angle from the exit may be produced by neutral effluents which are emitted within a plume describable conservatively by a cosine function to the first power.

\section{APPLICATIONS}

As an application of the above, we have considered the possible contamination hazards of the proposed installation of the Xe ion discharge system on a meteorological satellite that includes instruments with radiator surfaces at temperatures of about $100 \mathrm{~K}$. The $100 \mathrm{~K}$ surface is at a distance of $1 \mathrm{~m}$ at an angle of $80^{\circ}$ from the plasma source exit. According to the designers (ref.1), the generator operates in the following manner.

The Xe ion system release $0.5 \mathrm{~cm}^{3} / \mathrm{min}$ of Xe $(\mathrm{M}=131$ $\mathrm{g} / \mathrm{mole}$ ) at a temperature of $300 \mathrm{~K}$ and produces a thrust of a few milliNewtons. The energy of the produced cold plasma is $15 \mathrm{eV}$ and of the high-energy plasma is $28 \mathrm{eV}$. The dipole electromagnetic field is mostly contained within the genera- tor and is of relatively low magnitude; the internally sputtered materials are $\mathrm{Mo}$, $\mathrm{Re}$, iron ( $\mathrm{Fe}$ ), calcium ( $\mathrm{Ca}$ ), platinum $(\mathrm{Pt})$, strontium $(\mathrm{Sr})$, tantalum $(\mathrm{Ta})$, and $\mathrm{BaCo}_{3}$. The plasma energy at start-up and under transient conditions can be as high as $100 \mathrm{eV}$, sufficient for the Xe sputtering of several of the above materials. Test data from the engine operation in a vacuum chamber indicate no deposits or erosion on witness slides at normal temperature located at 40 and 6 degrees from the engine centerline at a distance of less than $30 \mathrm{~cm}$ from the exit plane. Some carbon and sodium were found on one of the slides mounted below the engine. The deposits were later attributed to backstreamed vacuum pump oil.

From the above data and the test data of the $\mathrm{Hg}$ thruster, one may conclude the following: the engine plasma with energies of 15 and $28 \mathrm{eV}$ will be contained within a narrow plume of less than 40 degrees and the ions will not impinge directly on a surface if that field of view (FOV) is unobstructed. Some of the less energetic ions can be directed by the electric field produced by the engine to adjacent spacecraft surfaces, but they will be neutralized and desorbed. Only a few will be held by surface forces and remain on the surfaces. A small amount of material will be sputtered in the engine and then released. The amount that can be sputtered is small because the threshold energies for the sputterable materials (ref. 6) are greater than $30 \mathrm{eV}$ and the available energies are less than $28 \mathrm{eV}$. However, at start-up and under transient conditions with energies of $100 \mathrm{eV}$, some materials may sputter. Such particles will be ejected within an angle of less than 10 degrees.

The arrival and the effects of the Xe neutrals and ions on the $100 \mathrm{~K}$ surface must be evaluated. Figure 5 plots the flux distribution $\Phi / \mathrm{m}\left(\mathrm{cm}^{-2}\right)$ as a function of the $X$ and $Y$ coordinates with the origin at a source that releases $\mathrm{m}(\mathrm{g} / \mathrm{s})$ of gas. The plot is for a cosine plume distribution $(n=1)$. It shows the locations of the $100 \mathrm{~K}$ surface and of the witness slides used to monitor during the tests. Other plots for $n=2$, 4 , and 5 in the equation are also shown for convenience.

The mass rate of Xe released corresponding to the given volume flow rate of $0.5 \mathrm{~cm}^{3} / \mathrm{min}$ is $\mathrm{m}=4.87 \times 10^{-5} \mathrm{~g} / \mathrm{s}$. For maximum spread of the plume; i.e., $n=1$ with $r=100$ and $\theta=80$, the flux at the cold surface is $2.67 \times 10^{-10} \mathrm{~g} / \mathrm{cm}^{2} / \mathrm{s}$, which is also obtainable from the plot, indicating $\phi / \mathrm{m}=5.5$ $\times 10^{-6} \mathrm{~cm}^{-2}$ at that location. The corresponding molecular flux is $1.23 \times 10^{12} \mathrm{~cm}^{-2} \mathrm{~s}^{-1}$. The adiabatic velocity is $318 \mathrm{~m}$ $\mathrm{s}$ so the density of the directional flux at the cold surface is $3.86 \times 10^{7} \mathrm{~cm}^{-3}$ and the equivalent pressure is 5.49 $\times 10^{-9}$ torr. The actual density and pressure accounting for molecular reflection are $3.86 \times 10^{8} \mathrm{~cm}^{-3}$ and $5.47 \times 10^{-7}$ torr, respectively.

With the above impinging parameters, if condensation were to occur at $100 \mathrm{~K}$, the $\mathrm{Xe}$ vapor pressure at that temperature would be 0.75 torr and the evaporation rate using Langmuir's equation would be $4.96 \times 10^{-2} \mathrm{~g} / \mathrm{cm}^{2} / \mathrm{s}$. For these conditions, the condensation cannot occur, since the condensate vapor pressure and the rate of condensate evaporation are greater than those impinging at the surface. 
The reflected flux from the surface, reflecting with a cosine distribution could impinge on a surface in its field of view. However, the condensation is again impossible if the surface temperature is higher than $100 \mathrm{~K}$.

A number of molecules or atoms can be held at the 100 $\mathrm{K}$ surface by van der Waal forces. An estimate can be fould using the method indicated above. Tests on the adsorption of $\mathrm{Xe}$ on palladium (Pd) indicated an adsorption activation energy of $E=4.5 \mathrm{Kcal} / \mathrm{mole}$ (ref. 7). Using this energy in the absence of data on Xe adsorption with $t=10 \times 10^{-13} \mathrm{~s}$ and $\mathrm{T}=100 \mathrm{~K}$, the residence time will be about $5.92 \times 10^{-4} \mathrm{~s}$. The atoms' density on the surface is them about $7.27 \times 10^{8}$ $\mathrm{cm}^{-2}$ using a sticking coefficient of 1 . A monolayer of Xe will consist of approximately $5.33 \times 10^{14}$ atoms $/ \mathrm{cm}^{2}$, since the Xe atom's diameter is $4.9 \times 10^{-8} \mathrm{~cm}$ and its cross section is then $1.87 \times 10^{-15} \mathrm{~cm}^{2}$. The adsorbed molecules could be about one millionth of those needed to form a monolayer. It can be expected, however, that based on other factors, the surface would be covered with a few monolayers.

\section{CONCLUSIONS}

A method to evaluate the effects of gases originating from plumes or other direct sources impinging on sensitive surfaces located within their field of view has been described. It has been applied to a specific arrangement of an $\mathrm{Xe}$ ion plasma generator with a thrust of a few $\mathrm{mN}$ located near a cryogenic surface.

The method to be employed for the analysis is based on experimentally derived plume descriptions of emitted lowpressure vented gases and on test results of plume distributions from a similar ion engine. Simple relations for gas flow, kinetic gas theory and other practical approaches to analyze contamination hazards have been employed.

For the example showing the application of an ion generator on a spacecraft, it has been concluded that:

- The Xe neutrals cannot condense on a surface at $100 \mathrm{~K}$ located $1 \mathrm{~m}$ away at an angle of 80 from the engine exit centerline;

- A fraction of a monolayer of Xe will be adsorbed on that surface;

- As indicated by tests described elsewhere, it is expected that the plasma produced by this generator - a cold plasma with an energy of about $15 \mathrm{eV}$ and a highenergy plasma of less than $30 \mathrm{eV}$ - will exit the engine within a narrower plume distribution than the spreadout plume of the neutral Xe;

- The flux of the narrow plasma plume on the cold surface will be lower than that of the neutrals, making condensation and adsorption less possible;
- The energetic ions will be contained within a field of view of less than 40 , as indicated by tests and will not impinge on a surface within that field;

- Electromagnetic fields created at the engine may direct the less energetic ions to some surfaces, but the surfaces will neutralize and desorb them, allowing only a few to remain;

- A small amount of sputtered material is expected to be released from the engine under transient conditions having energies higher than $30 \mathrm{eV}$. These will be ejected within an angle of less than $40^{\circ}$, and only a surface within this angle would be affected.

\section{REFERENCES}

1. Robson, R. R., W. S. Williamson et al., "Flight Model Discharge System," AFGL TR-87-0143, Hanscom AFB, April 1987.

2. Anon, "Evaluation of the Field and Particle Effluents from the SAMSO 601 (IAPS) Ion Auxiliary Propulsion System Experiment," report published by NASA Lewis Research Center.

3. Scialdone, J. J., "Flow Fields of Low Pressure Vent Exhausts," NASA Technical Memorandum 100738, NASA Goddard Space Flight Center, July 1989.

4. Beattie, J. R., J. N. Matossian, R. L. Poeschel, W. P. Rogers, and R. Martinelli, "Xenon Ion Propulsion Subsystem," AIAA-85-2012, AIAA/DGLR/JSASS 18th International Electric Propulsion Conference, Sept. 30, 1985, Alexandria, VA.

5. Cohen, H. A. and S. Lai, "Dischargiung the P78-2 Satellite Using Ions and Electrons," AIAA-82-0266, AIAA 20th Aerospace Science Meeting, Jan. 11, 1982, Orlando, FL.

6. Wehner, G. K. and G. S. Anderson, "The Nature of Physical Sputtering," Part I, Ch. 3 in Handbook of Thin Film Technology, ed. L. I. Maissel and R. Glang, McGraw-Hill, New York.

7. Moog, E. R. and M. B. Webb, "Xenon and Krypton Adsorption on Palladium (100)," Surface Science, Vol. 148, No. 2/3, Dec. 1982, North Holland Publishing Co., Amsterdam. 

Public reporting burden for this collection of inlormation is estimated to average 1 hour per response, including the time tor reviewing instructions, searching existing data sources. gathering Pulic reporis of and mainaning the data neoded, and compleing and 1204. Arlington. VA 22202-4302, and to the OHtice of Management and Budget. Paperwork Reduction Project (0704-0188), Washington. DC 20503.
1. AGENCY USE ONLY (Leave blank) 2. REPORT DATE
3. REPORT TYPE AND DATES COVERED May 1993 Technical Memorandum

\section{TITLE AND SUBTITLE}

Contamination Control and Plume Assessment of Low-Energy Thrusters 5. FUNDING NUMBERS

6. AUTHOR(S)

John J. Scialdone

7. PERFORMING ORGANIZATION NAME(S) AND ADDRESS(ES)

8. PERFORMING ORGANIZATION REPORT NUMBER

Goddard Space Flight Center 93E01024

Greenbelt, Maryland 20771

10. SPONSORING/MONITORING

9. SPONSORING/MONITORING AGENCY NAME(S) AND ADDRESS(ES) AGENCY REPORT NUMBER

National Aeronautics and Space Administration

Washington, D.C. $20546-0001$

TM-104585

11. SUPPLEMENTARY NOTES

12a. DISTRIBUTION/AVAILABILITY STATEMENT

12b. DISTRIBUTION CODE Unclassified-Unlimited

Subject Category 38

Report is available from the National Technical Information Service, U.S. Dept. of Commerce, 5285 Port Royal Road, Springfield, VA 22151; (703) 557-4650.

13. ABSTRACT (Maximum 200 words)

Potential contamination of a spacecraft cryogenic surface by a xenon (Xe) ion generator (ref. 1) has been evaluated. The analysis involves the description of the plume exhausted from the generator with its relative component fluxes on the spacecraft surfaces, and verification of the conditions for condensation, adsorption, and sputtering at those locations. The data describing the plume fluxes and their effects on surfaces were obtained from two sources: the tests carried out with the Xe generator in a small vacuum chamber to indicate deposits and sputter on monitor slides; and the extensive tests with a mercury $(\mathrm{Hg})$ ion thruster (ref. 2) in a large vacuum chamber. The $\mathrm{Hg}$ thruster tests provided data on the neutrals, on low-energy ion fluxes, on high-energy ion fluxes, and on sputtered materials at several locations within the plume.

spacecraft contamination, plasma ion thruster engine, plume components, spacecraft

16. PRICE CODE surfaces

17. SECURITY CLASSIFICATION
OF REPORT
Unclassified

18. SECURITY CLASSIFICATION
OF THIS PAGE
Unclassified
OF THIS PAGE
Unclassified
9. SECURITY CLASSIFICATION OF ABSTRACT Unclassified

20. LIMITATION OF ABSTRACT

Unlimited 